\title{
Should splenic autotransplantation be considered after total splenectomy due to trauma?
}

\section{Autoimplante esplênico deve ser considerado para pacientes submetidos à esplenectomia total por trauma?}

Daniel linhares Cardoso1; Florentino de Araújo Cardoso Filho, tCBC-CE2; Amanda Linhares Cardoso3; Marcelo lima Gonzaga4; ANTÔNIO JOSÉ GRANDE ${ }^{5}$

\section{A B S T R A C T}

\begin{abstract}
Trauma is a public health problem and the most common cause of death in people under the age of 45. In blunt abdominal trauma, the spleen is the most commonly injured organ. Splenectomy remains the most common treatment, especially in high-grade lesions, despite increased nonoperative treatment. Removal of the spleen leads to increased susceptibility to infections due to its role in the immune function. Postsplenectomy sepsis is an important complication and presents a high mortality rate. Patients undergoing splenectomy should be immunized for encapsulated germs, as these are the agents most commonly associated with such infections. Splenic autotransplantation is a simple procedure, which can be an alternative to reduce infection rates consequent to total splenectomy, and reduce costs related to hospitalizations. This review aims to provide evidence-based information on splenic autotransplantation and its impact on the prognosis of patients undergoing total splenectomy. We searched the Cochrane Library, Medline/PubMed, SciELO and Embase, from January 2017 to January 2018 and selected articles in English and Portuguese, dated from 1919 to 2017. We found that the adjusted risk of death in splenectomized patients is greater than that of the general population, and when total splenectomy is performed, splenic autotransplantation is the only method capable of preserving splenic function, avoiding infections, especially postsplenectomy sepsis. Health professionals should be familiar with the consequences of the method chosen to manage the patient suffering from splenic trauma.
\end{abstract}

Keywords: Trauma and Stressor Related Disorders. Spleen. Splenectomy. Sepsis. Transplantation, Autologous.

\section{INTRODUCTION}

$\mathrm{T}$ he spleen is a lymphoid organ with three functional compartments ${ }^{1}$. It is the solid organ most frequently injured in blunt abdominal traumas², mainly due to its location and its rich vascularization. Worldwide, blunt splenic trauma accounts for $25 \%$ of solid organ damage and has mortality rates between $7 \%$ and $18 \%{ }^{3}$.

In 1892, Riegner described a splenectomy in a 14-year-old individual after splenic trauma, which initiated the routine performance of this procedure ${ }^{4}$. Complications of splenectomy have been known for years. However, this was the only treatment in these cases. In 1919, Morris and Bullock reported high rates of infections in splenectomized rats 5 . In 1952, a study by
King and Schumacker Jr. related splenectomy to higher rates of sepsis due to the loss of splenic functions ${ }^{6}$. Only in 1968, Upadhyaya and Simpson proposed conservative treatment?

Traditionally, the spleen was considered disposable for four reasons: its function was not well established; It was believed that splenectomy did not bring harm; belief in its poor regeneration and the fact that minimal lesions may result in major hemorrhage ${ }^{8}$. Nowadays, even knowing the important functions of this organ, the negative consequences of its removal and the techniques that can preserve it, total splenectomy is still routinely performed, mainly due to patient's severity or surgeon's inexperience in managing the patient conservatively.

1 - University of Fortaleza, Faculty of Medicine, Fortaleza, CE, Brazil. 2 - General Hospital of Fortaleza, General Surgery, Fortaleza, Ceará, Brazil. 3 - Christus University (Unichristus), Faculty of Medicine, Fortaleza, Ceará, Brazil. 4 - Federal University of Ceará, Faculty of Medicine, Fortaleza, CE, Brazil. 5 - State University of Mato Grosso do Sul, Faculty of Medicine, Dourados, MS, Brazil. 
Cases of postsplenectomy fulminant infection have been reported up to more than 20 years after surgery and are predominantly caused by encapsulated germs ${ }^{9}$. In addition, the risk of developing Postsplenectomy sepsis at any age is 5\%, with mortality greater than $50 \%{ }^{10}$. Studies that propose criteria for indication for nonoperative treatment of splenic lesions of high grade ${ }^{11}$ aim mainly to maintain spleen functions ${ }^{10}$. Despite this, hemodynamic instability, presence of severe injuries in other organs and damage control are some indications for splenectomy independent of the degree of splenic injury ${ }^{3}$.

The purpose of this review is to provide evidencebased information regarding spleen autotransplantation as an alternative to complications of total splenectomy.

\section{METHODS}

From January 2017 to January 2018, we conducted searches in the following databases: Medline/ PubMed, SciELO, Embase and Cochrane Library. We use the following keywords controlled by the Virtual Health Library (VHL) through DeCS (Descriptors in Health Sciences) and MeSH (Medical Subject Headings): "autotransplantation", "injury" and "splenectomy". We found 1137 articles, of which we selected 19. We included articles in English and Portuguese dated from 1919 to 2017. We also performed manual search on the references of the included articles. We paid attention to articles of interest to professionals of various medical specialties.

\section{LITERATURE REVISION}

\section{Why the spleen?}

Morphology: the spleen is a lymphoid organ located posteriorly in the upper left quadrant of the abdomen, below the diaphragm and lateral to the great gastric curvature. It presents three functional histological compartments: red pulp, white pulp and marginal zone. The red pulp is a region rich in sinusoid capillaries, besides presenting the splenic cords, formed by plasma cells, macrophages, fibers, reticular cells and blood cells. The white pulp has an immune function, formed by the lymph nodes, with their respective germinative centers that make up the perimeter of the central arteriole, and by the periarterial lymphatic sheath, composed of T lymphocytes. The region of the extreme periphery of the white pulp contains memory B cells and is in direct contact with the perifollicular area, with presence of macrophages and fibroblasts ${ }^{1}$.

Function: the spleen has both hematological and immunological functions. An important lymphoid organ, it is the main area of early exposure of bacteria to the immune system. Being the only organ able to perform hemocateresis, filtering blood and withdrawing non-opsonized or insufficiently opsonized antigens, the spleen is specialized in producing antibodies in a short period of time. In the spleen, IgM synthesis occurs after exposure to antigens, being the largest producer of $\mathrm{IgM}$ in the body. Some of its functions are: first humoral immune response, lymphocyte reservoir, blood filtration, platelet and immature erythrocyte reservoir, hematopoiesis (fetal life), production of phagocytic substances, activation of the complement system, reuse of iron and inhibition of angiotensin ${ }^{12}$. The spleen is the most efficient organ in eliminating bacteria invested by $\lg G$ and is essential in the clearance of encapsulated bacteria not opsonized by antibodies or complement ${ }^{13}$. As part of the reticuloendothelial system and receiving $25 \%$ of cardiac output, it also plays a large role in the immediate immune response ${ }^{9}$. The spleen is an important site of production of properdin and tuftissin, opsonins responsible for initiating the alternative complement pathway and enhancing the phagocytic activity of polymorphonuclear leukocytes and mononuclear cells. Asplenic individuals present impaired activation of the complement by the alternative pathway, making them more susceptible to severe infection with fulminant bacteremia, pneumonia or meningitis when compared with those with normal splenic function. It is an important organ in the regulation of immune hemostasis, through its ability to relate innate and adaptive immunity, reducing the risk of infections ${ }^{1}$.

Terminology: impairment of splenic function is defined as hyposplenism, an acquired disorder that can be caused by various hematological and immunological diseases and sometimes accompanied by reduction in spleen size ${ }^{1}$. Asplenia refers to the absence of the spleen, a condition that may be congenital in the minority of 
cases, or the result of surgery, which is more common'. When, due to the extension of the traumatic lesions, total splenectomy is necessary, the deliberate heterotopic autotransplantation of the splenic tissue in the omentum pouch may lead to maintenance of the splenic function'. A similar phenomenon may occur spontaneously, and was first reported in 1939 and described as splenosis ${ }^{14}$. Possible factors that restrict the immune function of splenic implants include their small size and poor vascularity, which reduces contact between particulate antigens and phagocytes ${ }^{1}$. These small implants of splenic tissue (splenosis) are found in the peritoneum of $50 \%$ of patients who underwent splenectomy due to trauma. About $10 \%$ of these patients also have accessory spleens ${ }^{1}$. Splenectomy performed for hematologic disorder, such as hereditary spherocytosis, thalassemia or lymphoma, presents a higher risk of sepsis than trauma-related splenectomy. A potential factor for a lower rate of trauma-related postsplenectomy infection is the frequent existence of splenic implants and/or accessory spleens ${ }^{15}$. Unfortunately, the degree of protection offered by splenosis or accessory spleens is variable and unpredictable (Table 1).

Table 1. Concepts related to spleen and its changes.

\begin{tabular}{ll}
\hline \multicolumn{1}{c}{ Term } & \multicolumn{1}{c}{ Meaning } \\
\hline Hyposplenia & Decreased splenic function, usually caused by hematological or immunologic disease. \\
Asplenia & Absence of spleen by congenital disorder or, more commonly, post-surgical. \\
Hypersplenism & Increase in splenic function, leading to increased erythrocyte clearance. \\
Splenosis & $\begin{array}{l}\text { Small splenic tissue implants that can usually be seen after splenic rupture or surgical } \\
\text { handling. }\end{array}$ \\
Splenomegaly & Increase in the volume of the spleen. \\
Splenectomy & Partial or total surgical removal of the spleen.
\end{tabular}

Epidemiology: trauma is a public health issue and the most common cause of death in people under 45 years of age ${ }^{16}$. Abdominal trauma represents more than $10 \%$ of traumatic lesions ${ }^{12}$, and the spleen is the most commonly injured organ in blunt abdominal traumas ${ }^{2}$, but also susceptible to injuries by penetrating and iatrogenic mechanisms ${ }^{17}$. Approximately 25,000 surgical splenectomies are performed annually in the United States, and the total number of asplenic people in this country is currently estimated at one million ${ }^{13}$.

\section{When is splenectomy necessary?}

The American Association for the Surgery of Trauma (AAST) has established a grading scale for splenic lesions, now used worldwide to diagnose these traumas and define optimal treatment. It is established that splenic trauma grades | and || can be treated conservatively. Grades IV and V should be treated surgically. In grade III, both conservative and surgical treatment may be considered, the choice depends on the patient's clinical condition and the surgeon's experience. Different hemostatic methods have been described in the literature, but splenectomy remains the safest approach, since some patients requiring damage control surgery are on the verge of physiological collapse, sometimes presenting with hypothermia, acidosis and coagulopathy, poorly tolerating bleeding. Medical-legal reasons are also among the reasons why splenectomy remains the safest treatment ${ }^{11}$. There have been studies proposing to expand the indication of conservative therapy for splenic trauma of grades IV and $\mathrm{V}$ in specialized trauma centers. The availability of modern modalities of radiological diagnosis has helped to identify and characterize splenic lesions with greater precision, making them useful for guiding the decision-making process, and facilitating the decision between conservative or surgical management ${ }^{3}$. Gradually, due to the greater knowledge of splenic functions, more surgeons prefer a conservative approach (Table 2). 
Table 2. Degrees of splenic injury, according to the American Association for the Surgery of Trauma.

\begin{tabular}{|c|c|c|}
\hline & Degree & Description of the injury \\
\hline \multirow{2}{*}{1} & Hematoma & Subcapsular, <10\% surface area. \\
\hline & Laceration & Capsular tear, $<1 \mathrm{~cm}$ parenchymal depth. \\
\hline \multirow{2}{*}{$\|$} & Hematoma & Subcapsular, $10-50 \%$ surface área, intraparenchymal, $<5 \mathrm{~cm}$ in diameter. \\
\hline & Laceration & Capsular tear, $1-3 \mathrm{~cm}$ parenchymal depth that does not involve a trabecular vessel. \\
\hline \multirow[t]{2}{*}{ III } & Hematoma & $\begin{array}{l}\text { Subcapsular, }>50 \% \text { surface area or expanding; ruptured subcapsular or parecymal } \\
\text { hematoma; intraparenchymal hematoma } \geq 5 \mathrm{~cm} \text { or expanding. }\end{array}$ \\
\hline & Laceration & $>3 \mathrm{~cm}$ parenchymal depth or involving trabecular vessels. \\
\hline IV & Laceration & $\begin{array}{l}\text { Laceration involving segmental or hilar vessels producing major devascularization } \\
\text { ( }>25 \% \text { of spleen). }\end{array}$ \\
\hline \multirow{2}{*}{ V } & Hematoma & Completely shattered spleen. \\
\hline & Laceration & Hilar vascular injury with devascularizes spleen. \\
\hline
\end{tabular}

Conservative treatment: nonoperative treatment should be chosen whenever possible ${ }^{18}$. The vast majority (60-90\%) of patients with splenic lesions are treated conservatively, with success rates above $80 \%{ }^{10}$. Maintaining splenic function is an important advantage of conservative therapy. The age of the patient, the institution's experience, the surgeon's experience and the type of trauma are also factors that can influence the chosen approach ${ }^{9}$. All patients treated non-surgically are advised not to play sports for at least two to three months and avoid contact sports for another three months. In addition, they are advised to seek immediate medical attention if they experience sudden abdominal pain ${ }^{18}$. It is necessary to be aware of the significant number of patients who develop secondary bleeding after initially conservative treatment attempts ${ }^{18}$. The risks of conservative therapy include: late bleeding, infections, need for blood transfusion and no identification of other intraabdominal lesions ${ }^{3}$. More than $90 \%$ of secondary splenic ruptures occur within ten days after the initial trauma. Secondary ruptures more than two weeks after the trauma are rare ${ }^{18}$. There are factors that predict failure of nonoperative treatment: hemodynamic instability, preexisting splenic disease, age greater than 55 years, degree of injury and extension of hemoperitoneum ${ }^{4}$. Disadvantages of nonoperative management include increased risk of occult injury, particularly hollow viscus lesion, disease related to eventual transfusion, and, when used, additional risks associated with embolization techniques.
The failure rate of conservative therapy is about $10 \%^{10}$. Early identification of patients at high risk for failure of conservative therapy (possibly requiring intervention or delayed splenectomy) is essential, since delayed recognition and treatment of late splenic ruptures leads to increased morbidity and mortality. High-grade splenic lesions (AAST grade III or higher), presence of extensive hemoperitoneum, signs of severe shock at admission, need for transfusion of one or more red cell concentrates and presence of traumatic brain injury are some of the criteria ${ }^{10}$.

The factors that contribute to the success of conservative management are the continuous monitoring of vital signs, serial reassessments of the patient and the possibility of transfusion when necessary. In addition, the hospital should have easy access to computed tomography with intravenous contrast administration and 24-hour coverage of interventional radiology. If the hospital is unable to meet these requirements, conservative therapy should not be chosen over surgery in cases where there is doubt about the ideal approach ${ }^{10}$.

Operative treatment: in unstable patients, operative management is mandatory, but whenever possible, surgery with splenic preservation should be performed. Partial resection may be attempted in cases where the lesion is limited to the lower pole of the spleen. Due to the more exposed position of the lower pole, it is believed that in most splenic lesions at least the upper part of the organ can be preserved, because it may be 
vascularized only by the short gastric vessels if the hilum has to be resected. In addition, in approximately $60 \%$ of patients, there is an upper pole artery, which makes this type of partial splenic preservation technically easier ${ }^{18}$.

In 2005, the Society for Surgery of the Alimentary Tract established guidelines suggesting that splenectomy due to trauma should only be indicated if the patient had hemodynamic instability, lost more than $1000 \mathrm{ml}$ of blood, required transfusion of two or more packed red blood cells or if there is evidence of ongoing bleeding ${ }^{1}$. Today, operative management is still indicated in case of hemodynamic instability or when there are associated intra-abdominal lesions that require surgical treatment.

\section{What are the consequences of splenectomy?}

Patients treated with total splenectomy have significantly higher rates of infection compared with patients whose spleen has been preserved, either after conservative or surgical treatment, and this difference is clinically and statistically significant ${ }^{18}$. Overwhelming Postsplenectomy Infection (OPSI) was the term popularized by Diamond, in $1969^{11}$, to describe the main long-term splenectomy complication. Currently, the risk of developing Overwhelming Postsplenectomy Sepsis (OPSS) at any age is $5 \%$ and can occur at any time after removal of the spleen, it occurs, in more than half of the cases, in the first two years ${ }^{9}$, with a mortality rate of more than $50 \%{ }^{17}$. It is believed that increased risks of infections are eternal, with the occurrence of fulminant infection reported more than 20 years after splenectomy ${ }^{19}$. The risk of OPSI in splenectomized patients is more than 50 times greater than in the general population ${ }^{20}$ and occurs after $0.5 \%$ of all splenectomies resulting from trauma. It is believed that approximately $25 \%$ of asplenic patients will develop severe infection at some time ${ }^{12}$.

OPSI is a medical emergency in which only immediate diagnosis and treatment can reduce mortality'. Most deaths occur within the first 24 hours $^{21}$. Asplenic patients should be informed that the presence of fever or severe symptoms, even without fever, may indicate a potentially fatal onset of infection ${ }^{13}$. More recent information suggests that when patients seek immediate medical attention, the mortality rate may be reduced to $10 \%$. More than $80 \%$ of deaths occur within the first 48 hours after hospital admission, illustrating the importance of early diagnosis and treatment ${ }^{15}$.

The agents most frequently responsible for postsplenectomy infections are encapsulated bacteria, such as Streptococcus pneumoniae, type-B Haemophilus influenzae and Neisseria meningitides ${ }^{9}$. Pneumococcal infection is the most common and has a mortality rate of up to $60 \%$. Risk of infection by encapsulated organisms are even greater in previously immunosuppressed or immunodeficient individuals ${ }^{9}$. In this context, the guidelines of the Surgical Infection Society recommend that patients undergoing splenectomy should receive pneumococcal and meningococcal vaccines and highrisk patients should also receive immunization against Haemophilus influenzae. Ideally, patients undergoing splenectomy due to trauma should receive these immunizations up to 14 days after spleen removal. A second dose of the pneumococcal vaccine may be required five years after the first dose. There is no current recommendation for additional doses of vaccination against type-B $H$. influenzae or meningococcus. Vaccination does not guarantee the same protection as splenic functions, since immunogenicity of vaccines is reduced in asplenic individuals. In addition, many patients do not receive immunization because they are unaware of the high risk of infection and have not been informed by the doctor, often because of lack of knowledge. Monitoring of titration of antibodies by the ELISA method may be useful to evaluate the need for revaccination". Asplenic individuals also have dysfunction of humoral immunity, with reduction in serum IgM antibodies and memory B cells, delaying the response to vaccination and decreasing their efficacy when compared with the response in people with intact spleen ${ }^{13}$.

The clinical presentation of postsplenectomy fulminant infection is nonspecific. Most commonly, patients have a short prodrome of fever, chills, pharyngitis, muscle aches, vomiting, or diarrhea. Often, there are no signs of infection, and the nasopharyngeal source is postulated ${ }^{15}$. In some cases, even if there is no localized infection focus, there is pneumonia or associated meningitis. The deterioration of the patient's condition is abrupt, occurring frequently within a few hours. Shock may develop and patients may present with disseminated intravascular coagulation and severe hypoglycemia ${ }^{13}$. 
Asplenic patients with fever should receive empirical antimicrobial therapy immediately ${ }^{13}$. This empirical approach can be changed to more specific treatment when the nature of the pathogen is known. Polymerase Chain Reaction, which allows simultaneous identification of the three main encapsulated bacteria causing OPSI, can be performed ${ }^{1}$. In addition, prophylactic antimicrobial therapy may be considered during the first two years after splenectomy, with prophylactic lifelong treatment for people who have postsplenectomy sepsis ${ }^{13}$. The use of antibacterial prophylaxis remains controversial and there is no consensus on its role, duration or efficacy ${ }^{3}$. The possibility of favoring the development of long-term resistant bacterial strains should be emphasized ${ }^{1}$. There is a need for appropriate immunization, patient education, and early intervention for treatment of postsplenectomy infections ${ }^{3}$.

Patients and their relatives should be instructed to notify the physician of any acute febrile illness, especially if associated with severe and systemic symptoms, and visits to tropical countries. The splenectomized patient is also more susceptible to infections by intra-erythrocyte organisms. For example, babesiosis, an infection transmitted by the tick Ixodes scapularis, is responsible for fulminant haemolytic fever in asplenic individuals. Hyperparasitism and delayed clearance of Plasmodium falciparum malaria have been reported in asplenic hosts 22,23 .

The approach by means of intense and careful monitoring of these patients has a favorable cost-benefit relation in terms of prevention and reduction of mortality ${ }^{24}$. It is believed that up to $84 \%$ of splenectomized individuals are unaware of their increased risks of acquiring sepsis ${ }^{25}$ and providing adequate information can reduce infectious complications $^{26}$.

\section{Is there an alternative?}

As an alternative to the consequences of total splenectomy, there is splenic autotransplantation, performed mainly in the large omentum (Figure 1), due to its rich vascularization, drainage through the portal system and high rate of bacterial clearance ${ }^{27}$. However, even the omental implants do not achieve blood perfusion equivalent to the original spleen ${ }^{28}$. This alternative requires approximately 16 weeks for the beginning of splenic functions and 30\% for splenic tissue to provide its complete function ${ }^{12}$, which corresponds to $35 \mathrm{~g}$ in humans, on average ${ }^{29}$. Patients with larger volumes of implanted splenic tissue had lower immunological changes ${ }^{28}$. Autotransplantation of splenic tissue into omental pouches is a relatively simple procedure, requiring no more than ten minutes from preparation of the fragments to suturing in the large omentum $^{30}$. However, it is important that the patient does not have any concomitant severe injury and is hemodynamically stable, without acidosis, hypothermia or coagulopathy.

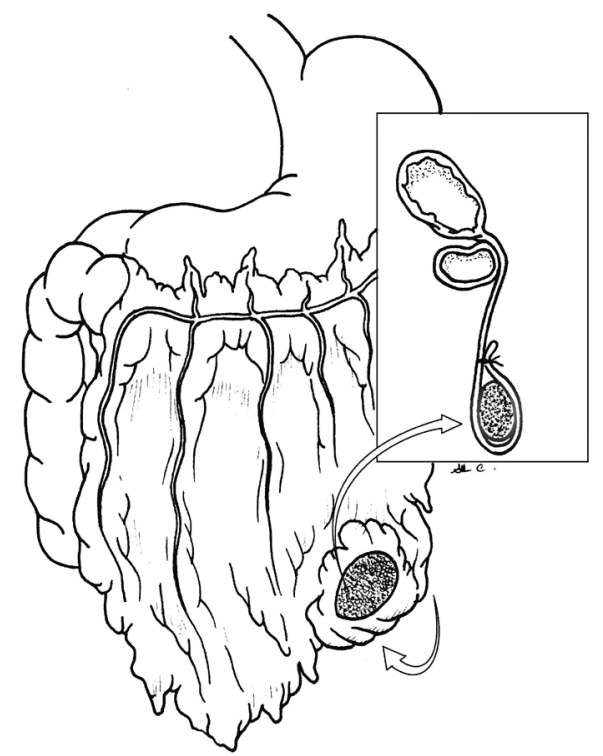

Figure 1. Schematic drawing of omental pouch containing implanted splenic tissue.

Studies, mainly experimental, macroscopic and microscopic, have proven morphological recovery and functional effectiveness of the splenic tissue implanted in the large omentum ${ }^{31-35}$. Hematological, immunological, scintigraphic and histopathological analyzes were performed. Some of the parameters evaluated were levels of hemoglobin, leukocytes, platelets, IgG, IgM, C3 protein and Howell-Jolly corpuscles, with favorable values in the groups in which splenic autotransplantation was performed. In addition, scintigraphy confirmed that implantation of splenic tissue in omental pouches is feasible ${ }^{36,37}$. Patients who underwent splenic autotransplantation in the large 
omentum have consistently greater splenic function than splenectomized patients in whom autotransplantation was not performed ${ }^{38}$.

The overall rate of complications following splenic autotransplantation is estimated at $2 \%$ to $3 \%$, similar to other routine surgical procedures ${ }^{28}$. Implant torsion, chronic anemia, postoperative intestinal obstruction and sub-phrenic abscesses due to implanted tissue necrosis and the ischemic nature of the implants have been reported as complications of intra-omental splenic autotransplantation ${ }^{27}$. However, new techniques are being improved in order to minimize the risks of complications ${ }^{27}$.

Splenic autotransplantation has debated efficacy, but represents the only possibility of preserving splenic function after severe trauma requiring splenectomy. If splenic lesions cannot be managed conservatively or by other surgical techniques, one can decide individually whether splenic autotransplantation should be attempted to preserve, at least partially, splenic function.

\title{
R E S U M O
}

\begin{abstract}
O trauma é um problema de saúde pública e a causa mais comum de óbito em pessoas com menos de 45 anos de idade. Nos traumas abdominais contusos, o baço é o órgão mais comumente lesado. A esplenectomia continua sendo o tratamento mais comum, especialmente em lesões de alto grau, apesar do aumento do tratamento não operatório. A remoção do baço gera aumento da suscetibilidade a infecções, devido ao seu papel na função imune. Sepse pós-esplenectomia é uma importante complicação e apresenta alta taxa de mortalidade. Pacientes submetidos à esplenectomia devem receber imunização para germes encapsulados, por serem os agentes mais comumente relacionados a essas infecções. Autoimplante esplênico é um procedimento simples, que pode ser alternativa para reduzir índices de infecção consequentes à esplenectomia total, e que pode reduzir custos relacionados à internações. Este trabalho de revisão objetiva prover informações baseadas em evidências sobre o autoimplante esplênico e seu impacto no prognóstico de pacientes submetidos à esplenectomia total. Foram realizadas buscas na Cochrane Library, Medline/PubMed, SciELO e Embase, de janeiro de 2017 a janeiro de 2018 e selecionados artigos em inglês e português, datados de 1919 a 2017. Verificou-se que o risco ajustado de morte em pacientes esplenectomizados é maior do que o da população geral, e quando a esplenectomia total é realizada, o autoimplante esplênico é o único método capaz de preservar a função esplênica, evitando infecções, principalmente sepse pósesplenectomia. Profissionais de saúde devem estar familiarizados com as consequências do método escolhido para manejar o paciente vítima de trauma esplênico.
\end{abstract}

Descritores: Transtornos Relacionados a Trauma e Fatores de Estresse. Baço. Esplenectomia. Sepse. Transplante Autólogo.

\section{REFERENCES}

1. Di Sabatino A, Carsetti R, Corazza GR. Postsplenectomy and hyposplenic states. Lancet. 2011;378(9785):86-97.

2. Fakhre GP, Berland T, Lube MW. One hundred consecutive splenectomies for trauma: is histologic evaluation really necessary? J Trauma. 2008;64(4):1139-41.

3. El-Matbouly M, Jabbour G, El-Menyar A, Peralta R, Abdelrahman $\mathrm{H}$, Zarour $\mathrm{A}$, et al. Blunt splenic trauma: assessment, management and outcomes. Surgeon. 2016;14(1):52-8.

4. Heuer M, Taeger $G$, Kaiser GM, Nast-Kolb D, Kühne CA, Ruchholtz S, Lefering $R$, Paul A, Lendemans S;
Trauma Registry of DGU. No further incidence of sepsis after splenectomy for severe trauma: a multiinstitutional experience of The trauma registry of the DGU with 1,630 patients. Eur J Med Res. 2010;15(6):258-65.

5. Morris DH, Bullock FD. The importance of the spleen in resistance to infection. Ann Surg. 1919;70(5):51321.

6. King $H$, Shumacker HB Jr. Splenic studies. I. Susceptibility to infection after splenectomy performed in infancy. Ann Surg. 1952;136(2):239-42.

7. Upadhyaya P. Conservative management of splenic trauma: history and current trends. Pediatr Surg Int. 2003;19(9-10):617-27.

8. Peitzman $A B$, Richardson JD. Surgical treatment of 
injuries to the solid abdominal organs: a 50-year perspective from the Journal of Trauma. J Trauma. 2010;69(5):1011-21.

9. Weledji EP. Benefits and risks of splenectomy. Int J Surg. 2014;12(2):113-9.

10. Olthof DC, van der Vlies CH, Goslings JC. Evidencebased management and controversies in blunt splenic trauma. Curr Trauma Rep. 2017;3(1):32-7.

11. Di Carlo I, Toro A. Splenic autotransplantation is always valid after splenectomy. J Invest Surg. 2017;30(6):401-2.

12. Chiotoroiu AL, Venter DM, Negoi I, Vartosu C, Plotogea O, Paun S, et al. Splenic implant assessment in trauma. Chirurgia (Bucur). 2014;109(6):731-40.

13. Rubin LG, Schaffner W. Care of the asplenic patient. N Engl J Med. 2014;371(4):349-56.

14. Buchbinder JH, Lipkoff CJ. Splenosis: multiple peritoneal splenic implants following abdominal injury: a report of a case and review of the literature. Surgery. 1939;6(6):927-34.

15. 15. Dionne B, Dehority W, Brett M, Howdieshell TR. The asplenic patient: post-insult immunocompetence, infection, and vaccination. Surg Infect (Larchmt). 2017;18(5):536-44.

16. The American Association for the Surgery of Trauma [Internet]. Trauma Facts. Chicago: The American Association for the Surgery of Trauma [cited 2017 out 10]. Available from: http://www.aast.org/traumafacts

17. Coldwell C, Hollingsworth A, Wilson $\mathrm{CH}$. Spleen conserving surgery versus splenectomy for injured patients with splenic trauma. Cochrane Database of Systematic Reviews. 2011, Issue 3. Art. No.: CD009042.

18. Gauer JM, Gerber-Paulet S, Seiler C, Schweizer WP. Twenty years of splenic preservation in trauma: lower early infection rate than in splenectomy. World J Surg. 2008;32(12):2730-5.

19. Marques RG, Petroianu A. Overwhelming postsplenectomy infection. Arq Gastroenterol. 2003;40(1):47-54.

20. Hansen K, Singer DB. Asplenic-hyposplenic overwhelming sepsis: postsplenectomy sepsis revisited. Pediatr Dev Pathol. 2001;4(2):105-21.

21. Holdsworth RJ, Irving AD, Cuschieri A.
Postsplenectomy sepsis and its mortality rate: actual versus perceived risks. Br J Surg. 1991;78(9):1031-8.

22. Rosner F, Zarrabi MH, Benach JL, Habicht GS. Babesiosis in splenectomized adults. Review of 22 reported cases. Am J Med. 1984;76(4):696-701

23. Demar M, Legrand E, Hommel D, Esterre P, Carme B. Plasmodium falciparum malaria in splenectomized patients: two case reports in French Guiana and a literature review. Am J Trop Med Hyg. 2004;71(3):290-3.

24. Woolley I, Jones P, Spelman D, Gold L. Costeffectiveness of a post-splenectomy registry for prevention of sepsis in the asplenic. Aust N Z J Public Health. 2006;30(6):558-61.

25. Brigden ML, Pattullo AL, Brown G. Pneumococcal vaccine administration associated with splenectomy: the need for improved education, documentation, and the use of a practical checklist. Am J Hematol. 2000; 65(1):25-9.

26. El-Alfy MS, El-Sayed MH. Overwhelming postsplenectomy infection: is quality of patient knowledge enough for prevention? Hematol J. 2004;5(1):77-80.

27. Di Carlo I, Pulvirenti E, Toro A. A new technique for spleen autotransplantation. Surg Innov. 2012;19(2):156-61.

28. Weber T, Hanisch E, Baum RP, Seufert RM. Late results of heterotopic autotransplantation of splenic tissue into the greater omentum. World I Surg. 1998;22(8):883-9.

29. Resende V, Petroianu A, Junior WC. Autotransplantation for treatment of severe splenic lesions. Emerg Radiol. 2002;9(4):208-12.

30. Resende V, Petroianu A. Estudo funcional tardio do auto-implante esplênico após trauma complexo do baço humano. Rev Col Bras Cir. 2001;28(3):167-72.

31. Braga AA, Malagó R, Anacleto TP, Silva CR, Andreollo $N A$, Fernandes FL. Histological aspects of autologous transplantation of different fragments of the spleen in rats. Acta Cir Bras. 2012;27(12):880-4.

32. Cardoso Filho FD, Feitosa RG, Fechine CO, Matos CM, Cardoso AL, Cardoso DL. Glucagonoma syndrome associated with necrolytic migratory erythema. Rev Assoc Med Bras (1992). 2015;61(3):203-6.

A3. Marques RG, Lucena SB, Caetano CE, de Sousa VO, 
Portela MC, Petroianu A. Blood clearance of HowellJolly bodies in an experimental autogenic splenic implant model. Br J Surg. 2014;101(7):820-7.

34. Teixeira FM, Fernandes BF, Rezende AB, Machado RRP, Alves CCS, Perobelli SM, et al. Staphylococcus aureus infection after splenectomy and splenic autotransplantation in BALB/C mice. Clin Exp Immunol. 2008;154(2):255-63.

35. Marques RG, Caetano CE, Diestel CF, Lima E, Portela MC, Oliveira AV, et al. Critical mass of splenic autotransplant needed for the development of phagocytic activity in rats. Clin Exp Immunol. 2012;170(1):77-85.

36. Karahan O, Eryilmaz MA, Okus A, Ay S, Unlu Y, Cayci $M$, et al. Evaluating the effectiveness of spleen autotransplantation into the liver and the omentum. Bratisl Lek Listy. 2013;114(11):610-5.

37. Soltani E, Aliakbarian M, Ghaffarzadegan K. Which common test should be used to assess spleen autotransplant effect? Ulus Travma Acil Cerrahi Derg. 2018;24(1):16-9.

38. Traub A, Giebink S, Smith C, Kuni CC, Brekke $M L$, Edlund $D$, et al. Splenic reticuloendothelial function after splenectomy, spleen repair, and spleen autotransplantation. N Engl J Med. 1987;317(25):1559-64.

Received in: 27/02/2018

Accepted for publication: 29/03/2018

Conflict of interest: none.

Source of funding: none.

\section{Mailing address:}

Daniel Cardoso

E-mail: daniellinharescardoso@gmail.com /

florentinocardoso@terra.com.br

\section{(cc) BY}

